\title{
Extreme population differentiation in a vulnerable slavemaking ant with a fragmented distribution
}

\author{
O. Sanllorente $\cdot$ R. L. Hammond • F. Ruano • \\ L. Keller $\cdot$ A. Tinaut
}

Received: 8 July 2009/Accepted: 6 February 2010/Published online: 19 March 2010

(C) Springer Science+Business Media B.V. 2010

\begin{abstract}
Understanding levels of population differentiation and inbreeding are important issues in conservation biology, especially for social Hymenoptera with fragmented and small population sizes. Isolated populations are more vulnerable to genetic loss and extinction than those with extended continuous distributions. However, small populations are not always a consequence of a recent reduction of their habitat. Thus, determining the history of population isolation and current patterns of genetic variation of a species is crucial for its conservation. Rossomyrmex minuchae is a slave-making ant with patchy distribution in South Eastern Spain and is classified as vulnerable by the IUCN. In contrast, the other three known species of the genus are presumed to show more uniform distributions. Here we investigate the genetic diversity and population structure of $R$. minuchae and compare it with that found in two other species of the genus: $R$. anatolicus and $R$. quandratinodum. We conclude that although genetic diversity of $R$. minuchae is low, there is no evidence of a recent bottleneck, suggesting a gradual and natural fragmentation process. We also show extreme population differentiation at nuclear and mitochondrial markers, and
\end{abstract}

O. Sanllorente and R. L. Hammond are joint first authors.

O. Sanllorente $(\bowtie) \cdot$ F. Ruano $\cdot$ A. Tinaut

Department of Animal Biology, University of Granada, 18071 Granada, Spain

e-mail: oli@ugr.es

R. L. Hammond

Department of Biological Sciences, University of Hull, Hull HU6 7RX, UK

L. Keller

Department of Ecology and Evolution, University of Lausanne, 1015 Lausanne, Switzerland isolation by distance at a local scale. Despite some evidence for inbreeding and low genetic variation within populations, we found almost no diploid males, a finding which contrasts with that expected in inbred Hymenoptera with single locus complementary sex determination. This could mean that sex is determined by another mechanism. We argue that continued low population size means that detrimental effects of inbreeding and low genetic variation are likely in the future. We suggest that a policy of artificial gene flow aimed at increasing within population variation is considered as a management option.

Keywords Rossomyrmex minuchae - Slave-making ant . Vulnerable species - Population differentiation .

Fragmented versus continuous distribution

\section{Introduction}

Terrestrial invertebrates are important components of ecosystems and their effective conservation raises issues distinct from those raised by vertebrates (Samways 1994, 2005; Thomas 1994; New 1995). Because invertebrates are not one homogeneous group, but a highly diverse group with enormous variation in life history and biology, their effective conservation requires a tailored approach. For example, social insects are arguably one of the most important invertebrate groups ecologically, and their ecological success is largely because they are social (Wilson 1971), but sociality can also be a problem when population size declines (Chapman and Bourke 2001). First, the limitation of reproduction to a few individuals per nest means there is a large disparity between census and effective population size. Thus, even though densities of individuals appear high the effective population size can be low. This 
can lead to an underestimation of demographic threats. Second, if sex is determined by a single locus complementary system (sl-CSD) (Cook and Crozier 1995; van Wilgenburg et al. 2006) a decrease in genetic variation will increase the likelihood of individuals being homozygous at the sex-determining locus with the effect that many diploid males are produced. As diploid males do not work and are generally sterile (Cook and Crozier 1995; Pamilo and Crozier 1997), their production damages colony productivity and increases extinction risk by an order of magnitude above that in inbred diploids (Zayed and Packer 2005). However, species with regular inbreeding may have alternative mechanisms of sex determination which lowers diploid male load (Crozier 1971; Beukeboom 1995).

Social parasites such as slave-makers rely on host species and are almost always rare relative to their host (but see Fischer-Blass et al. 2006). Because of this low density they are particularly susceptible to demographic and genetic problems associated with sociality. They are therefore important species to assess the impact of genetic threats to social insects as a whole. Furthermore, social insects at risk of extinction are often social parasites or slave-makers (http://www.iucnredlist.org) and so there are direct reasons for understanding more about their biology and ecology. Although slave-makers are not 'keystone' species in ecosystems, their highly specialized behaviour makes them worthy of conservation in their own right.

Rossomyrmex minuchae Tinaut, 1981 is a scarce slavemaking ant species that invades nests of Proformica longiseta Collingwood, 1978 to steal brood that develop as slaves (Ruano and Tinaut 1999). Its conservation is important for two reasons. First, it uses a unique method of slave-raiding, where slave-maker workers carry fellow workers to the target host nest rather than relying on chemical trail following (Ruano and Tinaut 1999). Second, it is endemic to south-western Spain and currently known from only three populations, each about 40-100 km apart (Sierra Nevada, Sierra de Gador and Sierra de Filabres; Ruano et al. 2007). The species is listed as vulnerable in the IUCN Red List of Threatened Species and as endangered in the Red Book of Spanish Invertebrates (Martínez-Ibáñez et al. 2006). In addition to this scarcity, there are other aspects of its biology that are likely to impact on genetic variation. Excavations suggest that $R$. minuchae nests are monogynous (Ruano and Tinaut 2005; Tinaut et al. 2010) so that if queens mate singly each colony would contain only three haploid genomes. Furthermore, Ruano and Tinaut (2005) found that males are attracted by female calling but, uncommonly for ants, individual males were observed mating with multiple sister females. The result of this mating behaviour is that new nests would be more related than if each sister female mated with a different male. Finally, in a given year only about $35 \%$ of the nests produce sexual offspring (Ruano and Tinaut 2005), further lowering the effective population size and making it difficult for females to attract males (Ruano and Tinaut 2005). Together these suggest that Rossomyrmex minuchae may be particularly vulnerable to genetic threats and so serve as an important case study on the genetic effects of small population size in ants.

Our aim is to identify likely survival risks for $R$. minuchae populations. Specifically, we assess the degree of genetic differentiation between populations, investigate inbreeding and whether diploid males occur, estimate the effective mating frequency of queens, and examine evidence for recent bottlenecks. Based on these analyses we make conservation recommendations. To do so we collected genetic samples from all known populations. Our sample sizes are necessarily small but they are also a remarkably complete sampling of a rare ant, with all known nests of the species sampled. We also compared $R$. minuchae genetic diversity and population structure to that found in two species of the same genus ( $R$. anatolicus Tinaut, 2007 and $R$. quandratinodum Xia \& Zheng, 1995). These species are found in the semi arid steppes of Central Asia (Anatolian desert in Turkey and Charyn plains in the east of Kazakhstan) and likely have more continuous distributions than $R$. minuchae. As species with isolated populations are more prone to genetic drift, inbreeding and extinction than those with extended continuous distributions (Frankham et al. 2002; Keller and Waller 2002), the Asian species should exhibit higher levels of genetic variation but lower population structuring than R. minuchae. All three Rossomyrmex species are monogynous and have similar mating and raiding behaviour (Marikovsky 1974; Ruano and Tinaut 1999; Tinaut et al. 2010), so differences in population genetics cannot be simply due to variation in these life-history traits.

\section{Materials and methods}

Study areas and field work

A total of 64 nests (Table 1) were sampled during the summers of 2004, 2006 and 2007 from the three known populations of Rossomyrmex minuchae: Sierra de Gador (SG: $n=30$ nests), Sierra de los Filabres (SF: $n=8$ nests) and Sierra Nevada (SN: $n=26$ nests, Fig. 1). These populations are located in high mountains at 1,9002,100 $\mathrm{m}$ a.s.1. and separated from each other by about $50 \mathrm{~km}$. For all nests we recorded UTM coordinates using a hand-held GPS (Garmin) and calculated straight line distances between nests by trigonometry. Workers (mean/ range $=5.7 / 4-8$ per nest; Table 1 ) were collected at nest entrances and stored in ethanol at $99 \%$. Due to the short period of emergence of sexuals during the course of our 
sampling, only four nests in SN (the best monitored population) were detected producing sexual offspring; we sampled $n=31$ males (mean/range $=7.8 / 7-8$ per nest) from these nests that were stored frozen at $-80^{\circ} \mathrm{C}$ until later dissection and genotyping. We dissected all males to assess seminal vesicle status. Males were considered reproductive when no morphological abnormality was observed and if seminal vesicles occupied the length of the last abdominal segment.

Two populations of $R$. anatolicus (Fig. 1) separated by $425 \mathrm{~km}$ were sampled in Turkey: Belembaçi beli, Konya province (BB; $n=4)$ and Ziyaret tepesi, Sivas province (ZT; $n=3$ ). One nest was sampled in 2006 and the other six in 2008. For $R$. quandratinodum only three nests could be sampled in June 2007 in the South eastern plains of Kazakhstan (near the Charyn canyon, named CC; Fig. 1). For both species eight workers per nest were analysed.

Microsatellite genotyping and mitochondrial sequencing

Total DNA was extracted from workers using the Puregene DNA Isolation Kit (Gentra Systems). Rossomyrmex workers were genotyped at 12 microsatellite loci using primers from Cataglyphis cursor: Ccur11, Ccur26, Ccur46, Ccur63b, Ccur76, Ccur89 and Ccur99 (Pearcy et al. 2004), Formica exsecta: FE11, FE19, FE37 and FE51 (Gyllenstrand et al. 2002) and Formica lugubris: FL12 (Chapuisat 1996). Males were genotyped at a subset of five loci (Ccur11, Ccur46, Ccur63b, FE19 and FE51). All loci were amplified by PCR in a $10 \mu$ reaction containing about $2.5 \mathrm{ng}$ of DNA, $0.2 \mathrm{nM}$ of each primer, $0.25 \mathrm{nM}$ of each dNTP, $1 \times$ Qiagen buffer and $2.5 \mathrm{mM}$ of $\mathrm{MgCl} 2$ and 0.5 units of Taq (Qiagen). PCR conditions were an initial denaturing step of $94^{\circ} \mathrm{C}$, followed by 11 'touch-down' cycles of: $94^{\circ} \mathrm{C}$ for $15 \mathrm{~s}, 55-45^{\circ} \mathrm{C}$ for $30 \mathrm{~s}\left(-1^{\circ} \mathrm{C}\right.$ per cycle) and $72^{\circ} \mathrm{C}$ for $30 \mathrm{~s}$, followed by 30 cycles of: $94^{\circ} \mathrm{C}$ for $15 \mathrm{~s}, 50^{\circ} \mathrm{C}$ for $15 \mathrm{~s}$ and $72^{\circ} \mathrm{C}$ for $30 \mathrm{~s}$. PCR products were sized using an $\mathrm{ABI} 3100$ sequencer and Genemapper software v 3.5 .
We amplified about $791 \mathrm{bp}$ of mitochondrial cytochrome oxidase I (COI) from one randomly selected worker per nest of $R$. minuchae $(n=64)$ using primers developed for $F$. exsecta: COI exsecta 2F: GGATCNCCAGANATNGCTTANCCTCG and COI exsecta 2R: TAATNGCAAAAACNGCTCCTA designed by B. Holzer (University of Lausanne) and the same reaction conditions and temperature profile used for microsatellites. PCR products were cleaned with QIAquick PCR purification kit (spin column format) before sequencing either by a commercial company (Microsynth, Switzerland or Macrogen, Korea) or by Servicio de Genómica (University of Córdoba, Spain). We aligned resulting sequences using ClustalW and investigated sequence differences with MEGA version 3.1 (Kumar et al. 2004).

Genetic diversity and population structure

Because workers within nests are related, and so not genetically independent, we constructed 1,000 resampled datasets by randomly selecting 1 worker per nest using the program RESAMPIND (pers. comm. Jérôme Goudet). Each resampled dataset was tested for departure from Hardy-Weinberg equilibrium, genotypic disequilibrium (the independence of loci), gene diversity $\left(\mathrm{H}_{\mathrm{S}}\right.$, the expected heterozygosity), allelic richness and allele frequencies with the program FSTAT 2.9.3.2 (Goudet 2002). All reported values of statistics, their standard errors and $p$ values were averaged over all resampled data sets. Allelic richness (with a standardised sample size of 3 nests per population) and $\mathrm{H}_{\mathrm{S}}$ were compared among populations and species using STATISTICA 7. We tested for genetic differentiation among populations using $F$-statistics (Weir and Cockerham $1984)$ also with FSTAT. $F_{\text {IS }}$ and $F_{\text {ST }}$ were calculated over all populations in each species except $F_{\mathrm{ST}}$ for $R$. quandratinodum, because we could only sample one population. Pairwise $F_{\mathrm{ST}}$ was also estimated for all population pairs of R. minuchae. Means and standard errors were jackknifed over loci and significant levels were determined by randomization (1,000 times) of alleles for $F_{\text {IS }}$ and genotypes

Table 1 Number of sampled nests $(N)$, number of workers analysed, allelic richness for an equalized sample of 3 nests $(A)$, gene diversity $\left(H_{\mathrm{S}}\right)$ and inbreeding coefficient $\left(F_{\mathrm{IS}}\right)$ of the three Rossomyrmex species studied. SE for $F_{\text {IS }}$ was not calculated (see text)

\begin{tabular}{llrrrrr}
\hline Species & Population & $N$ & Workers & $A \pm$ SE & $H_{\mathrm{S}} \pm \mathrm{SE}$ & $F_{\mathrm{IS}}$ \\
\hline R. minuchae & SG & 30 & 157 & $2.004 \pm 0.337$ & $0.366 \pm 0.102$ & 0.188 \\
& SF & 8 & 41 & $2.129 \pm 0.235$ & $0.446 \pm 0.076$ \\
R. anatolicus & SN & 26 & 170 & $1.669 \pm 0.210$ & $0.254 \pm 0.079$ & 0.176 \\
& BB & 4 & 32 & $2.458 \pm 0.351$ & $0.499 \pm 0.303$ & 0.069 \\
R. quandratinodum & ZT & CC & 3 & 24 & $3.212 \pm 0.335$ & $0.684 \pm 0.276$ \\
\hline
\end{tabular}


Fig. 1 Study areas: Spain (with three Rossomyrmex minuchae populations), Turkey (with two $R$. anatolicus populations) and Kazakhstan (one $R$. quandratinodum population) (made with PHOTOSHOP)

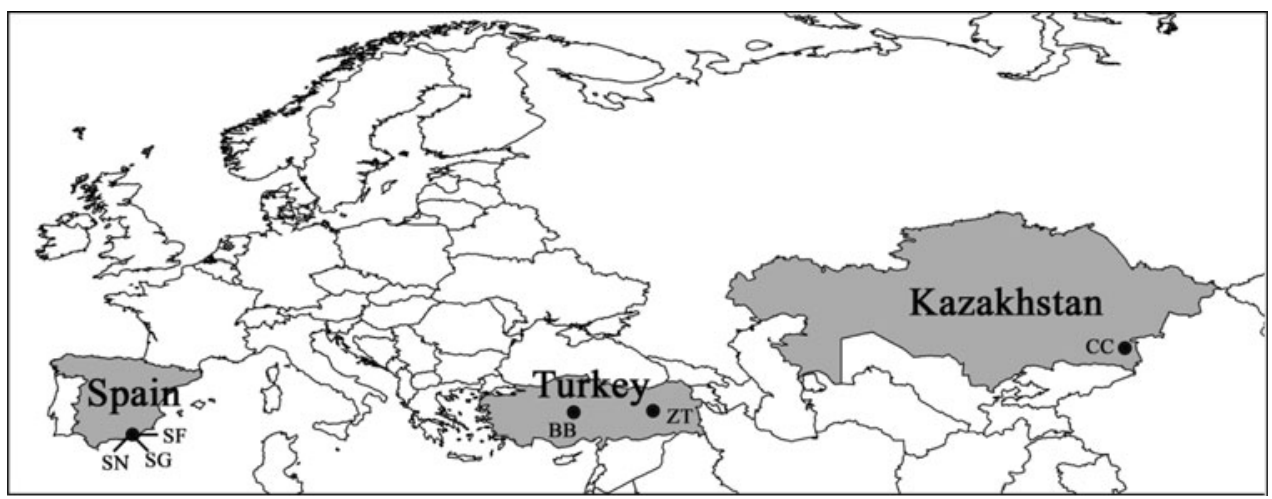

for $F_{\mathrm{ST}}$. In the case of pairwise $F_{\mathrm{ST}} 600$ permutations were performed applying Bonferroni corrections. Standard errors for $F_{\mathrm{IS}}$ and pairwise $F_{\mathrm{ST}}$ are not provided by the program and an estimate of the 1,000 resampled datasets would be meaningless (the greater the datasets, the smaller the error), so we do not give a value for this. As the range of possible $F_{\mathrm{ST}}$ values depends on the level of within population genetic variation, we calculated a standardized $F^{\prime}$ 'ST (Hedrick 2005) with the program RecodeData v.0.1 (Meirmans 2006).

To investigate the genetic structure of $R$. minuchae at a local scale, we tested for isolation by distance among colonies within populations by regression of a matrix of genetic distances $\left(F_{\mathrm{ST}} / 1-F_{\mathrm{ST}}\right)$ against a matrix of geographical distances (Rousset 1997) with the program GENEPOP (Raymond and Rousset 1995) in its web implementation (version 3.3). Significance levels were analysed using Mantel tests (Mantel 1967) for each correlation using 10,000 permutations.

Population bottlenecks

In order to know whether the low density of nests within the isolated populations of $R$. minuchae was due to recent bottlenecks, we performed the qualitative graphical method (Luikart et al. 1998), which requires no information on historical population size or historical levels of genetic variation.

\section{Mating system}

We explored the mating system of Rossomyrmex minuchae by inferring queen and mate genotypes from the worker offspring data and workers were assigned to patrilines using the software MATESOFT 1.0 (Moilanen et al. 2004). Given that we never found more than a single queen per nest during excavations of $R$. minuchae (Ruano and Tinaut 1999; Tinaut et al. 2010), whenever worker offspring genotypes did not fit monogyny, colonies were excluded from further analyses because the presence of strange genotypes probably reflects intraspecific raids, a behaviour observed in this species (pers. obs.). We tested whether social structure was consistent with monandry (Ruano and Tinaut 2005; Tinaut et al. 2010). If several queen genotypes were possible, we used a conservative approach and selected the queen genotype with the lowest number of patrilines that could explain worker genotypes. There were no colonies where worker offspring could not be assigned unambiguously to a patriline. We calculated the effective mating frequency according to Pamilo (1993) and the nondetection error, due to males sharing the same genotype according to Boomsma and Ratnieks (1996). Relatedness between queens and their mates was calculated with the programme RELATEDNESS 5.0 (Queller and Goodnight 1989) and, for cases where queens were not singly mated, between males mated to the same queen. In the calculations we estimated allele frequencies separately for each population, weighted nests equally and estimated standard errors by jackknifing over loci.

\section{Sex-biased dispersal}

We tested for sex-biased dispersal in SN and SG, but not in SF because too few nests were sampled. Similar to our isolation by distance analysis, we tested for a correlation between pairwise kinship coefficients and geographic distance matrices using Mantel tests. Kinship coefficients $\left(F_{i j}\right)$ were estimated for both queens and their mates using the program SPAGeDi (Hardy and Vekemans 2002) and analysed in separate Mantel tests. Where a queen was multiply mated we included all male genotypes and set their distance as zero. We chose $F_{i j}$ as it is insensitive to ploidy or inbreeding and so suitable for comparing the spatial genetic structure of males and queens (Hardy et al. 2008). We conducted Mantel tests with 10,000 permutations for significance levels in FSTAT.

Male ploidy and parentage

Males that were heterozygous at one locus or more were considered diploid. To estimate the probability of non 
detection of diploid males (i.e. diploid males homozygous at all loci) we determined the proportion of females having a homozygous genotype at all the loci genotyped in males.

We estimated the proportion of worker-produced males using genotype data with males classified as worker-produced if they carried at least one allele not present in their mother's genotype. The probability of detecting a worker produced male $\left(\mathrm{N}_{\mathrm{a}}\right)$ was calculated as in Foster et al. (2000) and the percentage of total males produced by workers (WPM) as in Brunner et al. (2005).

All results are expressed as mean $\pm \mathrm{SE}$.

\section{Results}

Genetic diversity

We found no significant deviation from Hardy-Weinberg expectations or evidence for associations between alleles at different loci in any of the populations/species. As shown in Tables 2 and 3, locus Ccur26 did not amplify in SG and SF populations of $R$. minuchae nor Ccur76 and FE11 in $R$. anatolicus. There was considerable differentiation between populations in $R$. minuchae, $\mathrm{SN}$ being the population with the lowest percentage of private alleles $(29.6 \%$; Table 2$)$. The percentage of private allele was intermediate in SF $(37.5 \%)$ and the highest $(56.4 \%)$ in SG. Furthermore, in SN six loci were monomorphic, three in SG and two in SF. In $R$. anatolicus and $R$. quandratinodum only locus (FL12) was monomorphic and it was fixed for a different allele than in $R$. minuchae. Over all loci, R. minuchae and $R$. anatolicus shared 12 alleles, $R$. minuchae and $R$. quandratinodum 11 alleles and $R$. anatolicus and $R$. quandratinodum 10 alleles (Table 3).
The overall allelic richness (A) was $1.93( \pm 0.23 \mathrm{SE})$ for $R$. minuchae, 2.84 ( $\pm 0.32 \mathrm{SE})$ for $R$. anatolicus and 2.29 ( $\pm 0.23 \mathrm{SE}$ ) for $R$. quandratinodum (Table 1$)$. The mean allelic richness was similar in the three species (KruskalWallis test, $H=4.89 ; P=0.09$ ) while $R$. anatolicus had a significant higher value than $R$. minuchae (LSD test, $t=$ $-2.33 ; P=0.032$ ). No significant differences in allelic richness were found among $R$. minuchae populations (ANOVA test, $F=0.80 ; P=0.46$ ) or between both $R$. anatolicus populations $(t=-1.55 ; P=0.14)$.

The mean gene diversity $\left(\mathrm{H}_{\mathrm{S}}\right)$ in $R$. minuchae was 0.35 ( $\pm 0.08 \mathrm{SE}), 0.66( \pm 0.07 \mathrm{SE})$ in $R$. anatolicus and 0.49 ( $\pm 0.07 \mathrm{SE}$ ) in $R$. quandratinodum (Table 1 ). As for allelic richness, $\mathrm{H}_{\mathrm{S}}$ in $R$. anatolicus was significantly higher than in $R$. minuchae and also than in $R$. quandratinodum (Kruskal-Wallis test, $H=8.30 ; P=0.016$ ). No significant differences in $H_{\mathrm{S}}$ were detected among the three $R$. minuchae populations (ANOVA test, $F=1.19$; $P=0.32$ ) and both $R$. anatolicus populations (Wilcoxon test, $W=61 ; P=0.077)$.

\section{Population structure}

The high level of differentiation found for the distribution of alleles in R. minuchae was also reflected in other measures. The overall $F_{\mathrm{ST}}$ value was $0.605( \pm 0.096 \mathrm{SE}$; $P=0.001)$ and pairwise estimates ranged from a maximum of 0.650 between SG and SN to 0.508 between SN and SG (Table 4). These values are very high given that the maximum value of $F$ ' ${ }_{\mathrm{ST}}$, which is equal to the mean within population level of homozygosity (Hedrick 2005), was 0.680 .

There was also some significant genetic differentiation at a local scale. In SG the genetic distance between

Table 2 Allele distribution among $R$. minuchae populations (number of sampled nests)

\begin{tabular}{llll}
\hline Locus & SG $(30)$ & SN $(26)$ & SF $(8)$ \\
\hline Ccur11 & $\mathbf{2 6 3}, \mathbf{2 6 5}$ & $283,285,287,289$ & $\mathbf{2 3 5}, \mathbf{2 5 3}, \mathbf{2 5 7}, 283,285,287,289, \mathbf{2 9 1}, \mathbf{2 9 3}$ \\
Ccur26 & NA & 139 & NA \\
Ccur46 & $171,173, \mathbf{1 7 5}, \mathbf{1 7 9}, \mathbf{1 8 5}, \mathbf{1 8 7}, \mathbf{1 8 9}$ & $\mathbf{1 6 1}, 171,173$ & $\mathbf{1 5 7}, 171$ \\
Ccur63 & $173, \mathbf{1 7 9}, \mathbf{1 8 1}, \mathbf{1 9 3}, 195,197,199$ & $199,201, \mathbf{2 0 3}, \mathbf{2 0 5}$ & $173, \mathbf{1 7 5}, \mathbf{1 9 1}, 195,197,199,201$ \\
Ccur76 & 164,166 & 164 & $\mathbf{1 5 4}, \mathbf{1 5 8}, 164,166$ \\
Ccur89 & $\mathbf{1 3 7}$ & $\mathbf{1 2 5}$ & $\mathbf{1 4 1}$ \\
Ccur99 & 114,120 & 120 & $114, \mathbf{1 1 8}, 120$ \\
FE11 & 285 & 289 & 285,289 \\
FE19 & $\mathbf{2 1 3}, \mathbf{2 1 5}, 217,219, \mathbf{2 2 5}, \mathbf{2 2 7}, \mathbf{2 2 9}$ & $219,221, \mathbf{2 2 3}$ & $\mathbf{2 1 1}, 217,219,221$ \\
FE37 & $\mathbf{1 1 5}, 121,123, \mathbf{1 2 5}$ & 119,121 & $119,121,123$ \\
FE51 & $110, \mathbf{1 1 2}, \mathbf{1 1 4}, \mathbf{1 1 6}, \mathbf{1 1 8}$ & $\mathbf{1 0 0}, \mathbf{1 0 2}, 104, \mathbf{1 0 6}, 110$ & $\mathbf{9 6}, 104, \mathbf{1 0 8}, 110$ \\
FL12 & 99 & 99 & 99
\end{tabular}

Private alleles marked in bold

NA locus not amplified 
Table 3 Allele distribution among the three Rossomyrmex species (number of sampled nests)

\begin{tabular}{|c|c|c|c|}
\hline Locus & R. minuchae (64) & R. anatolicus (7) & R. quandratinodum (3) \\
\hline Ccur11 & $235,253,257, \mathbf{2 6 3}, \mathbf{2 6 5}, \mathbf{2 8 3}, \mathbf{2 8 5}, \mathbf{2 8 7}, \mathbf{2 8 9}, \mathbf{2 9 1}, \mathbf{2 9 3}$ & $239,243,245,247,249,269$ & $235,253,257$ \\
\hline Ccur26 & 139 & $101, \mathbf{1 0 7}, \mathbf{1 0 9}, \mathbf{1 1 1}, \mathbf{1 1 3}, \mathbf{1 1 5}$ & $\mathbf{9 7}, \mathbf{9 9}, 101$ \\
\hline Ccur46 & $157, \mathbf{1 6 1}, \mathbf{1 7 1}, \mathbf{1 7 3}, \mathbf{1 7 5}, \mathbf{1 7 9}, \mathbf{1 8 5}, \mathbf{1 8 7}, \mathbf{1 8 9}$ & $151, \mathbf{1 5 3}, \mathbf{1 5 5}, 157$ & $147,149,151$ \\
\hline Ccur63 & 173, 175, 179, 181, 191, 193, 195, 197, 199, 201, 205 & $173,175, \mathbf{1 7 7}, 179,181, \mathbf{1 8 3}$ & 171, 173 \\
\hline Ccur76 & $\mathbf{1 5 4}, \mathbf{1 5 8}, 164,166$ & NA & $164,174,184$ \\
\hline Ccur89 & $125, \mathbf{1 3 7}, \mathbf{1 4 1}$ & $117,119, \mathbf{1 2 1}, 125$ & $117,119, \mathbf{1 2 3}$ \\
\hline Ccur99 & $114,118,120$ & $\mathbf{9 6}, \mathbf{1 0 4}, 114, \mathbf{1 1 6}, 118,120, \mathbf{1 2 2}, \mathbf{1 2 4}$ & $\mathbf{9 2}, \mathbf{9 8}, \mathbf{1 0 0}, \mathbf{1 0 2}, 118$ \\
\hline FE11 & 285,289 & NA & 285,289 \\
\hline FE19 & $211,213, \mathbf{2 1 5}, 217,219,221, \mathbf{2 2 3}, \mathbf{2 2 5}, \mathbf{2 2 7}, \mathbf{2 2 9}$ & $\mathbf{1 8 7}, \mathbf{1 9 7}, \mathbf{2 0 3}, \mathbf{2 0 5}, \mathbf{2 0 7}, 213,219,221$ & $211,217,219$ \\
\hline FE37 & $115,119,121,123,125$ & $\mathbf{1 0 3}, \mathbf{1 0 5}, \mathbf{1 0 7}, 109,111$ & 109,111 \\
\hline FE51 & $96, \mathbf{1 0 0}, \mathbf{1 0 2}, \mathbf{1 0 4}, \mathbf{1 0 6}, \mathbf{1 0 8}, \mathbf{1 1 0}, \mathbf{1 1 2}, \mathbf{1 1 4}, \mathbf{1 1 6}, 118$ & $88, \mathbf{9 0}, \mathbf{9 2}, \mathbf{9 4}, 96$ & 86, 88 \\
\hline FL12 & 99 & 89 & 89 \\
\hline
\end{tabular}

Private alleles marked in bold

$N A$ locus not amplified

Table 4 Pairwise $\mathrm{F}_{\mathrm{ST}}$ in $R$. minuchae (above diagonal)

\begin{tabular}{llll}
\hline & SG & SF & SN \\
\hline SG & & 0.5079547 & 0.6499504 \\
SF & $*$ & & 0.5243215 \\
SN & $*$ & $*$ &
\end{tabular}

Significance from zero (below diagonal) is Bonferroni corrected $* P<0.05$

colonies increased significantly with increasing geographic distance, providing clear evidence of isolation by distance (Mantel test, $P=0.002$ ), whereas in $\mathrm{SN}$ the differentiation was not significant (Mantel test, $P=0.064$ ). SF had insufficient sampled nests to permit a robust test.

In $R$. anatolicus, there was a moderate and not significant genetic differentiation between the two populations sampled $\left(F_{\mathrm{ST}}=0.233 \pm 0.090 \mathrm{SE} ; P=0.068\right)$. None of the populations in any species showed significantly positive values of inbreeding ( $F_{\mathrm{IS}}$ all tests $P>0.05$; Table 1$)$. However, the power of our analysis was relatively low because of limited sample sizes (in particular for $R$. anatolicus and R. quandratinodum).

Population bottlenecks

The analysis of allele frequency classes showed that for all three $R$. minuchae populations rare alleles (those with frequencies lower than 0.1) were the most common. This is contrary to the expected pattern for bottlenecked populations where alleles of intermediate frequency classes should be overrepresented as rare alleles are more likely to be lost during the bottleneck. There is therefore no evidence for a distortion in allele frequencies stemming from recent bottleneck in any of the studied populations (Fig. 2).

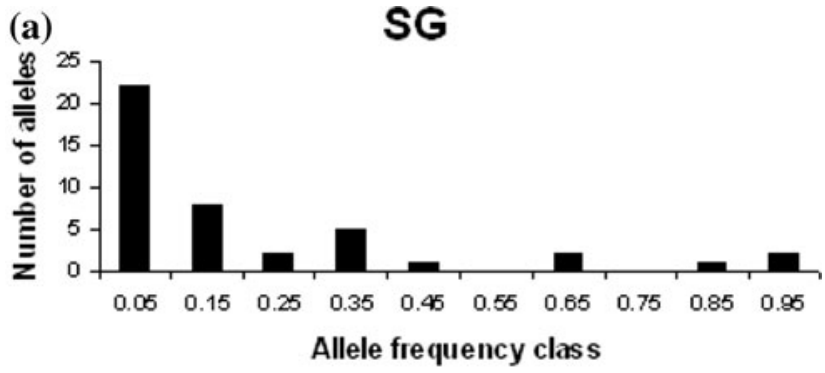

(b) SF

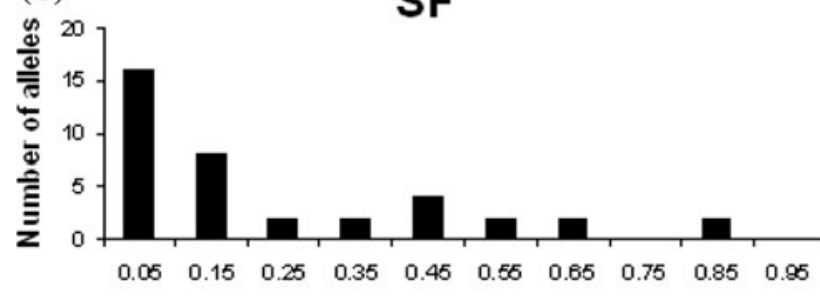

Allele frequency class

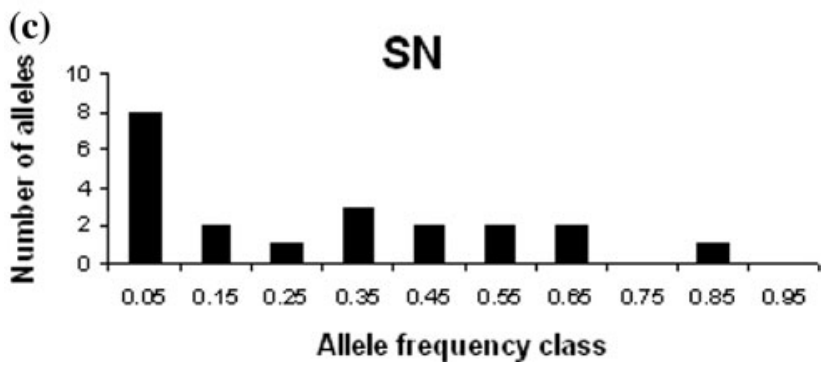

Fig. 2 Allele frequency distribution from the three known populations of $R$. minuchae: $\mathrm{SG}$ (a), SF (b) and $\mathrm{SN}$ (c) (made with MICROSOFT EXCEL)

Mitochondrial sequences

Alignment of $791 \mathrm{bp}$ of COI from $64 R$. minuchae workers revealed seven haplotypes, three in SG (GenBank 
accession numbers GU147935, GU147936 and GU181201), two in SN (accession nos. GU147937 and GU181204) and two in SF (accession nos. GU181202 and GU181203). Within populations, haplotypes differed only by one or two (in SG) base pairs but when comparing among populations, haplotypes were differentiated: $3.4 \%$ between $\mathrm{SN}$ and SG, $2.6 \%$ between SF and SG and $1.1 \%$ between SF and SN.

\section{Mating system of $R$. minuchae}

There was only one nest (in SF) in which worker genotypes violated the assumption of monogyny, suggesting that intraspecific raids are not common ( 1 out of 64 nests). In $51 \%$ of the nests queens were singly mated and in $38 \%$ they were doubly mated (Fig. 3). Higher mating frequencies were found in only seven nests ( 3 in six nests and 5 in one nest). The effective mating frequency was similar in the three populations $($ mean/range $=1.33 / 1.28-1.38$; the likelihood of two patrilines having identical multilocus haplotypes was higher in SF (0.195), than in SN or SG ( 0.074 and 0.033 , respectively). The relatedness between queens and their mates was not significantly different from zero: $r=0.153 \pm 0.247$ in $\mathrm{SN}(t=0.506, \mathrm{df}=41$, $P=0.615)$ in SG, $r=0.134 \pm 0.323(t=0.322, \mathrm{df}=$ $38, P=0.750)$ and $r=-0.057 \pm 0.267$ in $\mathrm{SF}(t=$ -0.208 , $\mathrm{df}=9, P=0.840$ ). In addition, males mated to the same queen were on average not related to each other as relatedness between them was not significantly greater than zero $(r=0.343 \pm 0.171 ; \quad t=1.467, \quad \mathrm{df}=24$, $P=0.155 \quad$ for $\quad$ SG, $\quad r=0.262 \pm 0.317 ; \quad t=0.709$, df $=12, \quad P=0.492$ for $\mathrm{SN}$ and $r=0.315 \pm 0.229$; $t=0.1 .048, \mathrm{df}=5, P=0.342$ for $\mathrm{SF}$ ).

Analysis of isolation by distance for queens and their mates separately showed population differences, with significant isolation by distance for males and queens in SG $\left(\mathrm{n}_{\text {males }}=52 ; r^{2}=0.084 ; \quad P<0.01 ; n_{\text {queens }}=30 ; r^{2}=\right.$ $0.047 ; P<0.01$ ), however, no trend was found in $\mathrm{SN}$ $\left(n_{\text {males }}=39 ; r^{2}=0.002 ; P=0.20 ; n_{\text {queens }}=26 ; r^{2}=\right.$ $0.009 ; P=0.09)$.

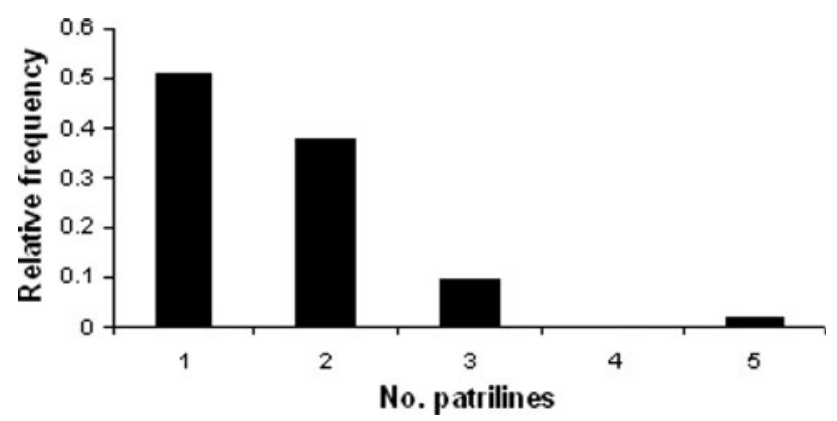

Fig. 3 Number of patrilines observed in $R$. minuchae nests (made with MICROSOFT EXCEL)
Male ploidy and parentage in $R$. minuchae

Only one of the 31 males (3.2\%) was found to be diploid and only at one locus (Ccur63b; Table 5). As $85 \%$ of the genotyped workers were heterozygous for at least for one locus, the probability of detecting diploid males was high. Dissections showed normal seminal vesicles in all males, including the diploid male.

Males produced by workers were found in three of the four colonies that reared males. The overall proportion of worker-produced males was $40 \%$, with values ranging from 0 to $72 \%$ per colony (Table 5 ).

\section{Discussion}

Our analysis reveals that the three populations of Rossomyrmex minuchae are genetically very distinct from each other at both microsatellite loci and mtDNA sequences. Even on a local scale differentiation was evident with significant isolation by distance in one of the populations and marginally in another, suggesting dispersal is restricted to some extent. The level of differentiation found in $R$. minuchae is higher than reported for other scarce and isolated ant species (Goropashnaya et al. 2001; Mäki-Petäys et al. 2005; Mäki-Petäys and Breen 2007), a finding that points to long-term isolation of its populations, rather than isolation because of recent habitat fragmentation (Sundström et al. 2005). This latter point is supported by our bottleneck analysis which provided no evidence of recent population reductions. The finding of extreme differentiation in $R$. minuchae can probably be accounted by its enslaved 'host' Proformica longiseta being restricted to high altitude habitats and that the three populations have been isolated since the intervening habitat became inhospitable because of warming during some of the Pleistocene interglacials.

Genetic differentiation on such a local scale is surprising given that it generally only occurs in polygynous species (Ross and Keller 1995) where mated queens disperse on foot from their natal nest. In monogynous species there are only very few reports of high structuring, a notable

Table 5 Males produced by $R$. minuchae workers

\begin{tabular}{lllll}
\hline Nest & Nd & Nm & Na & WPM \\
\hline A & 2 & 6 & 3.14 & 64 \\
B & 3 & 8 & 4.18 & 72 \\
C & 0 & 8 & 4.02 & 0 \\
D & 1 & 8 & 4.06 & 25 \\
\hline
\end{tabular}

$\mathrm{Nd}$ is the number of males carrying an informative allele, $\mathrm{Nm}$ is the number of haploid genotyped males, $\mathrm{Na}$ is the number of assignable males and WPM is the percentage of males produced by workers 
exception being Cataglyphis cursor where colonies reproduce by fission (Clémencet et al. 2005). However, we found a significant isolation by distance for males and females in SG (but no significant relationship in $\mathrm{SN}$ ), suggesting that dispersal is likely limited in both male and female $R$. minuchae. Interestingly in most ants dispersal is typically male-biased (Sundström et al. 2003; Hardy et al. 2008), although extremely limited male dispersal has been reported in Cardiocondyla ants because some males are wingless (ergatoid) and mate in their own nest (Schrempf et al. 2005) (but winged dispersing males (Heinze et al. 1998) are also produced so it is unknown to what extent males contribute to gene flow in Cardiocondyla). The finding of limited male dispersal is in line with the low proportion of $R$. minuchae colonies observed producing sexuals each year (Ruano and Tinaut 2005). This means that few nests would have available queens for males to mate with and so males should tend to congregate in the same nests even though they can fly long distances. Therefore, related males may well congregate outside the same nests waiting for unmated females to emerge. As well as low male dispersal, single males mating repeatedly with different queens from the same nest (Ruano and Tinaut 2005) would likely add to population viscosity. Overall there is little doubt that dispersal of both sexes is restricted and populations are highly structured. In contrast, gene flow in two slave making ants (Harpagoxenus sublaevis and Protomognathus americanus, Brandt et al. 2007) showed malebiased gene flow and female philopatry (wingless queens). Mating and dispersal behaviour therefore seem to vary among parasitic ants.

Given that the populations are effectively isolated, that within population gene flow of both sexes is restricted, and that numbers of nests within populations are small, one would expect evidence of inbreeding. Consistent with this, $F_{\text {Is }}$ was positive (although not significantly so). Interestingly, despite the evidence of some inbreeding diploid males were rare with only one out of 31 males diploid. This low level of diploid male production may have a number of explanations. First, the frequency of diploid males may be underestimated as only adult males were genotyped. Since in some species diploid males are selectively removed before adulthood (Woyke 1963) they may have remained undetected. Second, $R$. minuchae may not have a simple slCSD mechanism of sex determination. Although most social Hymenoptera studied seem compatible with slCSD (van Wilgenburg et al. 2006) some species regularly undergoing inbreeding probably have other mechanisms of sex determination (Buschinger 1989). Indeed, Cardiocondyla obscuriour, an ant with intranidal brother-sister mating, successfully produces haploid male eggs and adults, so slCSD can be reasonably excluded (Schrempf et al. 2006). Another possible strategy to reduce inbreeding would be queens mating more than once, and, as estimated here, doubly mated queens are not uncommon. However, further studies will be required to determine the mechanisms of sex determination in $R$. minuchae.

The levels of genetic variation in $R$. minuchae were low in comparison to $R$. anatolicus, which had higher levels of allelic richness and gene diversity. In addition, the levels of genetic differentiation between populations of $R$. anatolicus were smaller than among $R$. minuchae populations despite an almost 10-fold greater distance (425 vs. $\sim 50 \mathrm{~km}$ ). This likely reflects a history of long-term fragmentation for $R$. minuchae, compared to a more continuous distribution for $R$. anatolicus. Similar patterns have been reported between small and isolated populations of Formica lugubris from Ireland and continuous populations from Finland (Mäki-Petäys and Breen 2007). What is clear is that levels of genetic variation within populations of $R$. minuchae are low compared to its closely related Turkish species. Given that we could only collect three nests of $R$. quandratinodum we could not test population structure and so further studies are needed.

How do our findings influence the possibility of managing of $R$. minuchae populations to ensure their survival? The genetic differentiation between the three known populations is sufficient for them to be considered separate subspecies, perhaps even species, as they show considerable differentiation at mtDNA and at multiple nuclear loci, including many fixed differences. As such, conventional wisdom would have them managed as separate units (Moritz 1994) so as to conserve the genetic diversity among populations (e.g. Loftis et al. 2009; Mockford et al. 2007; Pabijan et al. 2005). In contrast, detrimental effects of inbreeding in small populations are widely known (Frankham et al. 2002; Keller and Waller 2002), so one must balance the idea of preserving genetic diversity-and the status quo-with the possibility of alleviating detrimental effects by introducing new alleles from another population. Importantly, this issue is relevant to any declining and fragmenting social species with genetically differentiated populations, such as Plagiolepis xene (Trontti et al. 2006) or Bombus muscorum (Darvill et al. 2006). The degree of nuclear differentiation between known populations in $R$. minuchae suggests that valuable new genetic variation could be introduced into each population by translocating nests or sexual offspring. However, the risks of potentially negative effects such as out-breeding depression or disease transmission would need to be carefully considered before such management was undertaken. Although we did not find direct evidence for inbreeding negative effects, the small sample size and the apparently low dispersal of sexuals suggest that the future for these ants is bleak. Deciding between preserving conventional management units or being more adventurous and interventionist depends on 
what is deemed more important: conserving genetically distinct units based on genetic markers or conserving ants with a highly specific slave raiding behaviour?

Acknowledgements We thank the directorate of the National Park of Sierra Nevada for allowing us to sample there. A. Fernández, C. Karaman and Y. Kaz for helping us in nest search and excavations in Spain, Turkey and Kazakhstan, respectively. F. Mier and Y. Kaz kindly helped us with bureaucracy in Kazakhstan. J.G. Martínez offered technical help and J.D. Ibáñez-Álamo created the map. We also thank two anonymous reviewers for very useful comments. This research was supported by Ministerio de Medio Ambiente, Organismo Autónomo Parques Nacionales, project ref: 78/2003, a FPU grant to O.S. (Ministerio de Educación), the Plan Propio of the University of Granada and the Swiss NSF.

\section{References}

Beukeboom L (1995) Sex determination in Hymenoptera-a need for genetic and molecular studies. Bioessays 17:813-817

Boomsma JJ, Ratnieks FLW (1996) Paternity in eusocial Hymenoptera. Phil Trans R Soc B 351:947-975

Brandt M, Fischer-Blass B, Heinze J, Foitzik S (2007) Population structure and the co-evolution between social parasites and their hosts. Mol Ecol 16:2063-2078

Brunner E, Trindl A, Falk KH, Heinze J, D'Ettorre P (2005) Reproductive conflict in social insects: male production by workers in a slave-making ant. Evolution 59:2480-2482

Buschinger A (1989) Evolution, speciation, and inbreeding in the parasitic ant genus Epimyrma (Hymenoptera, Formicidae). J Evol Biol 2:265-283

Chapman RE, Bourke AFG (2001) The influence of sociality on the conservation biology of social insects. Ecol Lett 4:650-662

Chapuisat M (1996) Characterization of microsatellite loci in Formica lugubris and their variability in other ant species. Mol Ecol 5:560-599

Clémencet J, Viginier B, Doums C (2005) Hierarchical analysis of population genetic structure in the monogynous ant Cataglyphis cursor using microsatellite and mitochondrial DNA markers. Mol Ecol 14:3735-3744

Cook JM, Crozier RH (1995) Sex determination and population biology in the Hymenoptera. TREE 10:281-286

Crozier RH (1971) Heterozygosity and sex determination in haplodiploidy. Am Nat 105:399-412

Darvill B, Ellis JS, Lye GC, Goulson D (2006) Population structure and inbreeding in a rare and declining bumblebee, Bombus muscorum (Hymenoptera: Apidae). Mol Ecol 15:601-611

Fischer-Blass B, Heinze J, Foitzik S (2006) Microsatellite analysis reveals strong but differential impact of a social parasite on its two host species. Mol Ecol 15:863-872

Foster KR, Ratnieks FLW, Raybould AF (2000) Do hornets have zombie workers? Mol Ecol 9:735-742

Frankham R, Ballou JD, Briscoe DA (2002) Introduction to conservation genetics. Cambridge University Press, Cambridge, UK

Goropashnaya AV, Seppä P, Pamilo P (2001) Social and genetic characteristics of geographically isolated populations in the ant Formica cinerea. Mol Ecol 10:2807-2818

Goudet J (2002) FSTAT A program to estimate and test gene diversities and fixation indices (Version 2932) Available from www.unilch/izea/softwares/fstathtml

Gyllenstrand N, Gertsch PJ, Pamilo P (2002) Polymophic microsatellite DNA markers in the ant Formica exsecta. Mol Ecol Notes 2:67-69
Hardy OJ, Vekemans X (2002) SPAGeDi: a versatile computer program to analyse spatial genetic structure at the individual or population levels. Mol Ecol 13:3621-3632

Hardy OJ, Pearcy M, Aron S (2008) Small-scale spatial genetic structure in an ant species with sex-biased dispersal. Biol J Linn Soc 93:465-473

Hedrick PW (2005) A standardized genetic differentiation measure. Evolution 59:1633-1638

Heinze J, Hölldobler B, Yamuchi K (1998) Male competition in Cardiocondyla ants. Behav Ecol Sociobiol 42:239-246

Keller LF, Waller DM (2002) Inbreeding effects in wild populations. TREE 17:230-241

Kumar S, Tamura K, Nei M (2004) MEGA3: integrated software for molecular evolutionary analysis and sequence alignment. Brief Bioinform 5:150-163

Loftis DG, Echelle AA, Koike H, Van Den Bussche RA, Minckley CO (2009) Genetic structure of wild populations of the endangered Desert Pupfish complex (Cyprinodontidae: Cyprinodon). Conserv Genet 10:453-463

Luikart G, Allendorf FW, Cornuet JM, Sherwin WB (1998) Distortion of allele frequency distributions provides a test for recent population bottlenecks. J Hered 89:238-247

Mäki-Petäys H, Breen J (2007) Genetic vulnerability of a remnant ant population. Conserv Genet 8:427-435

Mäki-Petäys H, Zakharov A, Viljakainen L, Corander J, Pamilo P (2005) Genetic changes associated to declining populations of Formica ants in fragmented forest landscape. Mol Ecol 14:733742

Mantel M (1967) The detection of disease clustering and a generalized regression approach. Cancer Res 27:209-220

Marikovsky PY (1974) The biology of the ant Rossomyrmex proformicarum K. W. Arnoldi (1928). Insect Soc 21:301308

Martínez-Ibáñez MD, Tinaut A, Ruano F (2006) Rossomyrmex minuchae Tinaut 1981. In: Verdú JR, Galante E (eds) Libro Rojo de los Invertebrados de España. Dirección General para la Biodiversidad Ministerio de Medio. Ambiente, Madrid, pp 1167 1170

Meirmans PG (2006) Using the AMOVA framework to estimate a standardized genetic differentiation measure. Evolution 60:2399-2402

Mockford SW, Herman TB, Snyder M, Wright JM (2007) Conservation genetics of Blanding's turtle and its application in the identification of evolutionarily significant units. Conserv Genet 8:209-219

Moilanen A, Sundström L, Pedersen JS (2004) MateSoft: a program for deducing parental genotypes and estimating mating system statistics in haplodiploid species. Mol Ecol Notes 4:795-797

Moritz C (1994) Defining evolutionarily-significant-units for conservation. TREE 9:373-375

New TR (1995) An introduction to invertebrate conservation biology. Oxford University Press, Oxford

Pabijan M, Babik W, Rafinski J (2005) Conservation units in northeastern populations of the Alpine newt (Triturus alpestris). Conserv Genet 6:307-312

Pamilo P (1993) Polyandry and allele frequency differences between sexes in the ant Formica aquilonia. Heredity 70:472-480

Pamilo P, Crozier RH (1997) Population biology of social insect conservation. Mem Mus Vic 56:411-419

Pearcy M, Clemencet J, Chameron S, Aron S, Doums C (2004) Characterization of nuclear DNA microsatellite markers in the ant Cataglyphis cursor. Mol Ecol Notes 4:642-644

Queller DC, Goodnight KF (1989) Estimating relatedness using genetic markers. Evolution 43:258-275

Raymond M, Rousset F (1995) GENEPOP: population genetics software for exact tests and ecumenicism. J Hered 86:248-249 
Ross KG, Keller L (1995) Ecology and evolution of social organization: insights from fire ants and other highly eusocial insects. Annu Rev Ecol Syst 26:631-656

Rousset F (1997) Genetic differentiation and estimation of gene flow from F-statistics under isolation by distance. Genetics 145:12191228

Ruano F, Tinaut A (1999) Raid process activity pattern and influence of abiotic conditions in Rossomyrmex minuchae (Hymenoptera: Formicidae) a slave-maker species. Insect Soc 46:341-347

Ruano F, Tinaut A (2005) Mating behaviour in a slave-making ant Rossomyrmex minuchae (Hymenoptera Formicidae). Naturwissenschaften 92:328-331

Ruano F, Tinaut A, Sanllorente O, Fernández-Zambrano A (2007) Nuevas localidades para Rossomyrmex minuchae (Hymenoptera Formicidae). Bol Asoc esp Ent 31:209-211

Samways MJ (1994) Insect conservation biology. Chapman \& Hall, London

Samways MJ (2005) Insect diversity conservation. Cambridge University Press, Cambridge

Schrempf A, Reber C, Tinaut A, Heinze J (2005) Inbreeding and local mate competition in the ant Cardiocondyla batesii. Behav Ecol Sociobiol 57:502-510

Schrempf A, Aron S, Heinze J (2006) Sex determination and inbreeding depression in an ant with regular sib-mating. Heredity 97:75-80

Sundström L, Keller L, Chapuisat M (2003) Inbreeding and sex-biased gene flow in the ant Formica exsecta. Evolution 57:1552-1561
Sundström L, Seppä P, Pamilo P (2005) Genetic population structure and dispersal patterns in Formica ants-a review. Ann Zool Fennici 42:163-177

Thomas JA (1994) Why small cold-blooded insects pose different conservation problems to birds in modern landscapes. Ibis 137:S112-S119

Tinaut A, Ruano F, Sanllorente O, Fernández-Zambrano A, Karaman C and Kaz Y (2010) Nest composition and worker relatedness in three slave making ants of the genus Rossomyrmex Arnoldi and their Proformica Ruzsky hosts (Hymenoptera, Formicidae). Insect Sci 17

Trontti K, Aron S, Sundström L (2006) The genetic population structure of the ant Plagiolepis xene-implications for genetic vulnerability of obligate social parasites. Conserv Genet 7:241250

van Wilgenburg E, Driessen G, Beukeboom LW (2006) Single locus complementary sex determination in Hymenoptera: an "unintelligent" design? Front Zool 3:1

Weir BS, Cockerham CC (1984) Estimating F-statistics for the analysis of population structure. Evolution 38:1358-1370

Wilson EO (1971) The insect societies. Belknap Press, Cambridge, MA

Woyke J (1963) What happens to diploid drone larvae in a honeybee colony. J Apic Res 2:73-75

Zayed A, Packer L (2005) Complementary sex determination substantially increases extinction proneness of haplodiploid populations. Proc Natl Acad Sci USA 102:10742-10746 